\title{
Correction to: Roles of major and minor vein in leaf water deficit tolerance and structural properties in 11 temperate deciduous woody species
}

\author{
Kiyosada Kawai ${ }^{1} \cdot$ Naoki Okada $^{1}$
}

Published online: 20 February 2019

๑) Springer-Verlag GmbH Germany, part of Springer Nature 2019

Correction to: Trees (2018) 32(6):1573-1582.

https://doi.org/10.1007/s00468-018-1734-8

The original article contains an error in the given longitude of the study site in the section Materials and methods: The Ashiu Forest Research Station is located at $35.30^{\circ} \mathrm{N}$, $135.71^{\circ} \mathrm{E}$.

Publisher's Note Springer Nature remains neutral with regard to jurisdictional claims in published maps and institutional affiliations.

The original article can be found online at https://doi.org/10.1007/ s00468-018-1734-8.

Kiyosada Kawai

k.kawaikx@gmail.com

1 Graduate School of Agriculture, Kyoto University,

Kitashirakawa Oiwake-cho, Sakyo-ku, Kyoto 606-8502,

Japan 